\title{
Letter \\ Detrimental Effects of Doping Al and Ba on the Thermoelectric Performance of GeTe
}

\author{
Bhuvanesh Srinivasan *(D), Alain Gellé, Jean-François Halet, Catherine Boussard-Pledel and \\ Bruno Bureau
}

Univ. Rennes, ISCR UMR 6226, IPR UMR 6251, CNRS, 35000 Rennes, France; alain.gelle@univ-rennes1.fr (A.G.); jean-francois.halet@univ-rennes1.fr (J.-F.H.); catherine.boussard@univ-rennes1.fr (C.B.-P.); bruno.bureau@univ-rennes1.fr (B.B.)

* Correspondence: bhuvanesh.srinivasan@univ-rennes1.fr; Tel.: +33-223-233-688; Fax: +33-223-235-611

Received: 15 October 2018; Accepted: 9 November 2018; Published: 11 November 2018

\begin{abstract}
GeTe-based materials are emerging as viable alternatives to toxic PbTe-based thermoelectric materials. In order to evaluate the suitability of $\mathrm{Al}$ as dopant in thermoelectric $\mathrm{GeTe}$, a systematic study of thermoelectric properties of $\mathrm{Ge}_{1-x} \mathrm{Al}_{\mathrm{x}} \mathrm{Te}(x=0-0.08)$ alloys processed by Spark Plasma Sintering are presented here. Being isoelectronic to $\mathrm{Ge}_{1-x} \mathrm{In}_{x} \mathrm{Te}$ and $\mathrm{Ge}_{1-x} \mathrm{Ga}_{x} \mathrm{Te}$, which were reported with improved thermoelectric performances in the past, the $\mathrm{Ge}_{1-x} \mathrm{Al}_{x} \mathrm{Te}$ system is particularly focused (studied both experimentally and theoretically). Our results indicate that doping of Al to GeTe causes multiple effects: (i) increase in $p$-type charge carrier concentration; (ii) decrease in carrier mobility; (iii) reduction in thermopower and power factor; and (iv) suppression of thermal conductivity only at room temperature and not much significant change at higher temperature. First principles calculations reveal that Al-doping increases the energy separation between the two valence bands (loss of band convergence) in GeTe. These factors contribute for $\mathrm{Ge}_{1-x} \mathrm{Al}_{\mathrm{x}} \mathrm{Te}$ to exhibit a reduced thermoelectric figure of merit, unlike its In and Ga congeners. Additionally, divalent Ba-doping $\left[\mathrm{Ge}_{1-\mathrm{x}} \mathrm{Ba}_{\mathrm{x}} \mathrm{Te}(x=0-0.06)\right]$ is also studied.
\end{abstract}

Keywords: Thermoelectrics; GeTe; Al-doping; Ba-doping; loss of band convergence; lowered zT

\section{Introduction}

The generation, storage and transport of energy are among the greatest challenges, if not the most formidable challenge of all, for years to come. In this regard, thermoelectric (TE) materials and devices have drawn increasing interest and attention due to their potential to reversibly convert waste heat into electricity [1]. The TE material's efficiency is quantified by a dimensionless figure of merit, $z T=S^{2} \sigma T / \kappa$ where $S, \sigma, T$ and $\kappa$ are the Seebeck coefficient, electrical conductivity, absolute temperature and total thermal conductivity (sum of the electronic part, $\kappa_{\mathrm{e}}$, and the lattice part, $\kappa_{\text {latt }}$ ), respectively. Seebeck coefficient, electrical and thermal conductivity are inter-locked and there is a high degree of challenge to decouple the electronic and thermal transport [2]. To tackle these challenges, thermoelectric material research has recently flourished with the emergence of novel concepts of band engineering, nanostructuring and discoveries of various novel materials. Amongst the state-of-the-art TE materials, the extensively studied PbTe-based materials are limited by their toxicity for any practical applications, despite their high zT [3-6]. Recently, GeTe-based materials have emerged as a clear alternative choice, as they have proven to exhibit higher performance $(z T>1)$, if optimally doped with suitable elements [7-10]. Some of the strategies for GeTe-based materials to enhance the power factor $\left(S^{2} \sigma\right)$ and/or to suppress $\kappa_{\text {latt }}$ were adopted on compositions such as GeTe-AgSbTe 2 (TAGS) [11], GeTe-LiSbTe 2 [12], GeTe-AgInTe 2 [13],GeTe-AgSbSe ${ }_{2}$ [14], (GeTe) ${ }_{n} \mathrm{Sb}_{2} \mathrm{Te}_{3}$ [15], $\mathrm{Ge}_{1-x} \mathrm{~Pb}_{x} \mathrm{Te}$ [16], $\mathrm{Ge}_{1-x} \mathrm{Bi}_{x} \mathrm{Te}$ [17], $\left(\mathrm{Bi}_{2} \mathrm{Te}_{3}\right)_{n} \mathrm{Ge}_{1-x} \mathrm{~Pb}_{x} \mathrm{Te}$ [18], $\mathrm{Ge}_{1-x} \mathrm{In}_{\mathrm{x}} \mathrm{Te}$ [19], GeTe ${ }_{1-x} \mathrm{Se}$ [20], 
$\mathrm{Ge}_{1-\mathrm{x}} \mathrm{Sb}_{\mathrm{x}} \mathrm{Te}$ [21], $\mathrm{Ge}_{1-\mathrm{x}} \mathrm{Ag}_{\mathrm{x}} \mathrm{Te}$ [7], Ge $\mathrm{Ge}_{1-\mathrm{x}} \mathrm{Mn}_{\mathrm{x}} \mathrm{Te}$ [22], $\mathrm{Ge}_{1-\mathrm{x}-\mathrm{y}} \mathrm{Sn}_{\mathrm{x}} \mathrm{Pb}_{\mathrm{y}} \mathrm{Te}$ [23], $\mathrm{Ge}_{1-\mathrm{x}} \mathrm{Sb}_{\mathrm{x}} \mathrm{Te}_{1-\mathrm{y}} \mathrm{Se}_{\mathrm{y}}$ [24], GeTe-GeSe-GeS [25], $\mathrm{Ge}_{1-x-y} \mathrm{Bi}_{\mathrm{x}} \mathrm{Sb}_{\mathrm{y}} \mathrm{Te}$ [26], $\mathrm{Ge}_{1-\mathrm{x}-\mathrm{y}} \mathrm{Bi}_{\mathrm{x}} \mathrm{In}_{\mathrm{y}} \mathrm{Te}$ [9], $\mathrm{Ge}_{0.9-\mathrm{y}} \mathrm{Pb}_{0.1} \mathrm{Bi}_{\mathrm{y}} \mathrm{Te}$ [27], and more recently $\mathrm{Ge}_{1-x-y} \mathrm{Ga}_{x} \mathrm{Sb}_{y} \mathrm{Te}$ [8]. The crystal structure of these GeTe-based compounds undergoes a second-order ferroelectric structural transition from rhombohedral symmetry (low temperature phase) to cubic symmetry (high temperature phase) at around $700 \mathrm{~K} \mathrm{[10].}$

This work tries to explore the suitability of trivalent $\mathrm{Al}$ and divalent $\mathrm{Ba}$ as dopants for improving the thermoelectric performance of $\mathrm{GeTe}$. The choice of $\mathrm{Al}$ is particularly interesting, as its isoelectronic group-13 counterparts In and $\mathrm{Ga}$, if doped in optimum concentration, have proven to strongly enhance the thermoelectric performance of GeTe $[8,19]$.

\section{Materials and Methods}

The samples $\mathrm{Ge}_{1-x} \mathrm{Al}_{\mathrm{x}} \mathrm{Te}(x=0-0.08)$ and $\mathrm{Ge}_{1-\mathrm{x}} \mathrm{Ba}_{\mathrm{x}} \mathrm{Te}(x=0-0.06)$ were synthesized by vacuum sealed-tube melt processing. The obtained ingots were crushed into powder and consolidated by Spark Plasma sintering, SPS (FCT Systeme GmbH) at $773 \mathrm{~K}$ for 5 min under an axial pressure of $60 \mathrm{MPa}$. Details pertaining to experimental procedures, and materials characterization including electrical and thermal transport property measurements were discussed in detail in our previous works [6-9,28-30].

Density Functional Theory (DFT) calculations were performed to understand the effect of doping on the electronic states of GeTe. We used the projector-augmented-wave (PAW) approach [31] implemented in the Vienna ab initio simulation package (VASP) [32]. Calculations were performed using the generalized gradient approximation (GGA) for the exchange-correlation term parametrized by J. P. Perdew et al. [33] Similar to our previous work on Ga-doped GeTe [8], spin orbit coupling was included in the computations. As we were interested in high temperature behavior of doped $\mathrm{GeTe}$, calculations were performed on cubic structural models. Impurities were substituted to Ge atom in a $4 \times 4 \times 4$ super-cell. In order to understand the effect of $\mathrm{Al}$, the calculations were performed on $\mathrm{Al}_{2} \mathrm{Ge}_{62} \mathrm{Te}_{64}$ model (which is close to the experimental $\mathrm{Ge}_{0.97} \mathrm{Al}_{0.03} \mathrm{Te}$ composition). The distance between two $\mathrm{Al}$ atoms was $12.02 \AA$. For the irreducible cell, the Brillouin-zone integration was performed using a $25 \times 25 \times 25$ Monkhorst-Pack $k$-mesh. For the super-cell, we used a $3 \times 3 \times 3 k$-mesh for the atomic relaxation and a $7 \times 7 \times 7 k$-mesh for the electronic density of states (DOS) calculations.

\section{Results and Discussion}

The sharp reflections observed from X-ray diffraction (XRD) patterns for $\mathrm{Al}$ and $\mathrm{Ba}$ doped GeTe (Figure 1a,b, respectively) indicate the crystalline nature of the phases. The main reflections in both cases could be indexed to the rhombohedral ( $R 3 m$ ) GeTe phase (PDF\# 00-047-1079). The rhombohedral phase was further confirmed by the presence of double reflections [( $\left.\begin{array}{lll}0 & 2\end{array}\right)$ and (2 20 )] in the range of $2 \theta$ values between $41^{\circ}$ and $44^{\circ}$. A minor proportion of Ge-rich secondary phase was also present, as in agreement with the previous studies [7-9]. Based on the evolution of lattice parameters, the solubility limit for $\mathrm{Al}$ in GeTe was estimated to be $4 \mathrm{~mol} \%$. At higher content of $\mathrm{Al}$ (for $x>0.04$ ), $\mathrm{Al}_{2} \mathrm{Te}_{3}$ secondary phase started to appear and the GeTe main phase was not rhombohedral anymore (change of symmetry). The solubility limit for $\mathrm{Ba}$ in GeTe was found to be minimum ( $<2 \mathrm{~mol} \%)$, as $\mathrm{Ba}_{2} \mathrm{Ge}_{2} \mathrm{Te}_{5}$ phase existed in all the samples. This is unsurprising given the larger atomic radii of Ba compared to that of Ge. 

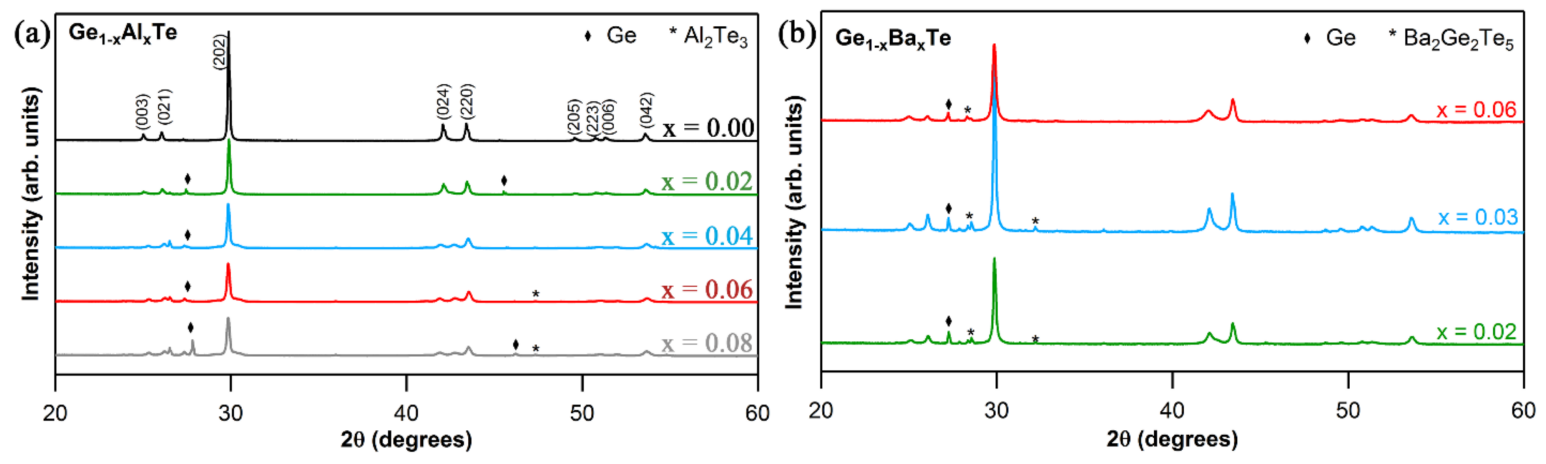

Figure 1. XRD patterns for $\mathrm{Ge}_{1-\mathrm{x}} \mathrm{Al}_{\mathrm{x}} \mathrm{Te}(\mathbf{a})$ and $\mathrm{Ge}_{1-\mathrm{x}} \mathrm{Ba}_{\mathrm{x}} \mathrm{Te}(\mathbf{b})$ systems.

Results from Hall measurements tabulating carrier concentration $(n)$ and mobility $(\mu)$ are presented in Table 1. Holes are the major charge carriers ( $p$-type), as the Hall voltage was found to be positive ( $p$-type) in both $\mathrm{Ge}_{1-x} \mathrm{Al}_{x} \mathrm{Te}$ and $\mathrm{Ge}_{1-x} \mathrm{Ba}_{x} \mathrm{Te}$ systems. Doping $\mathrm{Al}$ to $\mathrm{GeTe}$ provides extra holes to the system, which is reflected in the enhancement in charge carrier density. This is in contrast to the effect observed in In and $\mathrm{Ga}$ (isoelectronic with $\mathrm{Al}$ ) doped $\mathrm{GeTe}$, where In and Ga decreased the hole concentration by filling up Ge vacancies $[8,19]$. On the other hand, the mobility reduction can be attributed to the alloy scattering mechanism arising from the doping of $\mathrm{Al}$ and $\mathrm{Ba}$ to GeTe [34]. Due to decreased mobility, the electrical conductivity at room temperature was decreased for both $\mathrm{Ge}_{1-x} \mathrm{Al}_{x} \mathrm{Te}$ (Figure 2a) and $\mathrm{Ge}_{1-x} \mathrm{Ba}_{x} \mathrm{Te}$ (Figure 3a) systems with respect to that of GeTe. However, this trend was reversed at higher temperatures (cross over point at $450 \mathrm{~K}$ ) for Al-doped GeTe (Figure 2a). Such similar cases were reported for SnTe and PbTe-based materials, and those cross over effects were attributed to the changes in the electronic band structure with increasing temperature $[35,36]$. The electrical conductivity of all the samples decreased with increasing temperature, which suggests a degenerate semi-conducting behavior. The positive Seebeck coefficient confirmed the $p$-type charge carriers in $\mathrm{Al}$ and Ba doped GeTe (Figures 2 and 3), which was consistent with the Hall measurement results. The thermopowers of $\mathrm{Ge}_{1-x} \mathrm{Al}_{x} \mathrm{Te}_{\mathrm{and}} \mathrm{Ge}_{1-x} \mathrm{Ba}_{x} \mathrm{Te}$ monotonically increased with temperature. With increasing $\mathrm{Al}$ and $\mathrm{Ba}$ content, the change in $\mathrm{S}$ values at room temperature were not much evident, but they decreased significantly with increasing temperature, when compared to pristine GeTe. Doping of Al and Ba to GeTe decreased the S values, as it drastically inflated the hole carrier concentration. Consequently, the reduction of Seebeck coefficient with $\mathrm{Al}$ and Ba content also considerably affected the thermoelectric power factor (Figures 2 and 3). Finally, with $\mathrm{Al}$ and Ba doping, the total thermal conductivity decreased considerably at room temperature (Figures 2 and 3). However, it remained almost constant with temperature for Al-doped GeTe. The decreased thermopower significantly affected the thermoelectric figure of merit, $z T$ (Figures 2 and 3), which plunged with dopant concentration.

Table 1. Hall measurement results (at $\sim 300 \mathrm{~K}$ ) of carrier concentration $(n)$ and mobility $(\mu)$ for $\mathrm{Ge}_{1-\mathrm{x}} \mathrm{Al}_{\mathrm{x}} \mathrm{Te}(x=0.00-0.08)$ and $\mathrm{Ge}_{1-\mathrm{x}} \mathrm{Ba}_{\mathrm{x}} \mathrm{Te}(x=0.00-0.06)$ samples.

\begin{tabular}{ccc}
\hline Sample & Carrier Concentration, $\boldsymbol{n} \mathbf{( \mathbf { c m } ^ { - 3 } )}$ & Mobility, $\boldsymbol{\mu}\left(\mathbf{c m}^{\mathbf{2}} \mathbf{V}^{-\mathbf{1}} \mathbf{s}^{\mathbf{- 1}}\right)$ \\
\hline $\mathrm{GeTe}$ & $9.08 \times 10^{20}$ & 57.0 \\
$\mathrm{Ge}_{0.98} \mathrm{Al}_{0.02} \mathrm{Te}$ & $1.75 \times 10^{21}$ & 21.8 \\
$\mathrm{Ge}_{0.96} \mathrm{Al}_{0.04} \mathrm{Te}$ & $2.88 \times 10^{21}$ & 10.6 \\
$\mathrm{Ge}_{0.94} \mathrm{Al}_{0.06} \mathrm{Te}$ & $2.17 \times 10^{21}$ & 12.5 \\
$\mathrm{Ge}_{0.92} \mathrm{Al}_{0.08} \mathrm{Te}$ & $3.01 \times 10^{21}$ & 8.8 \\
$\mathrm{Ge}_{0.98} \mathrm{Ba}_{0.02} \mathrm{Te}$ & $9.78 \times 10^{20}$ & 28.2 \\
$\mathrm{Ge}_{0.97} \mathrm{Ba}_{0.03} \mathrm{Te}$ & $9.06 \times 10^{20}$ & 33.6 \\
$\mathrm{Ge}_{0.94} \mathrm{Ba}_{0.06} \mathrm{Te}$ & $1.62 \times 10^{21}$ & 16.2 \\
\hline
\end{tabular}



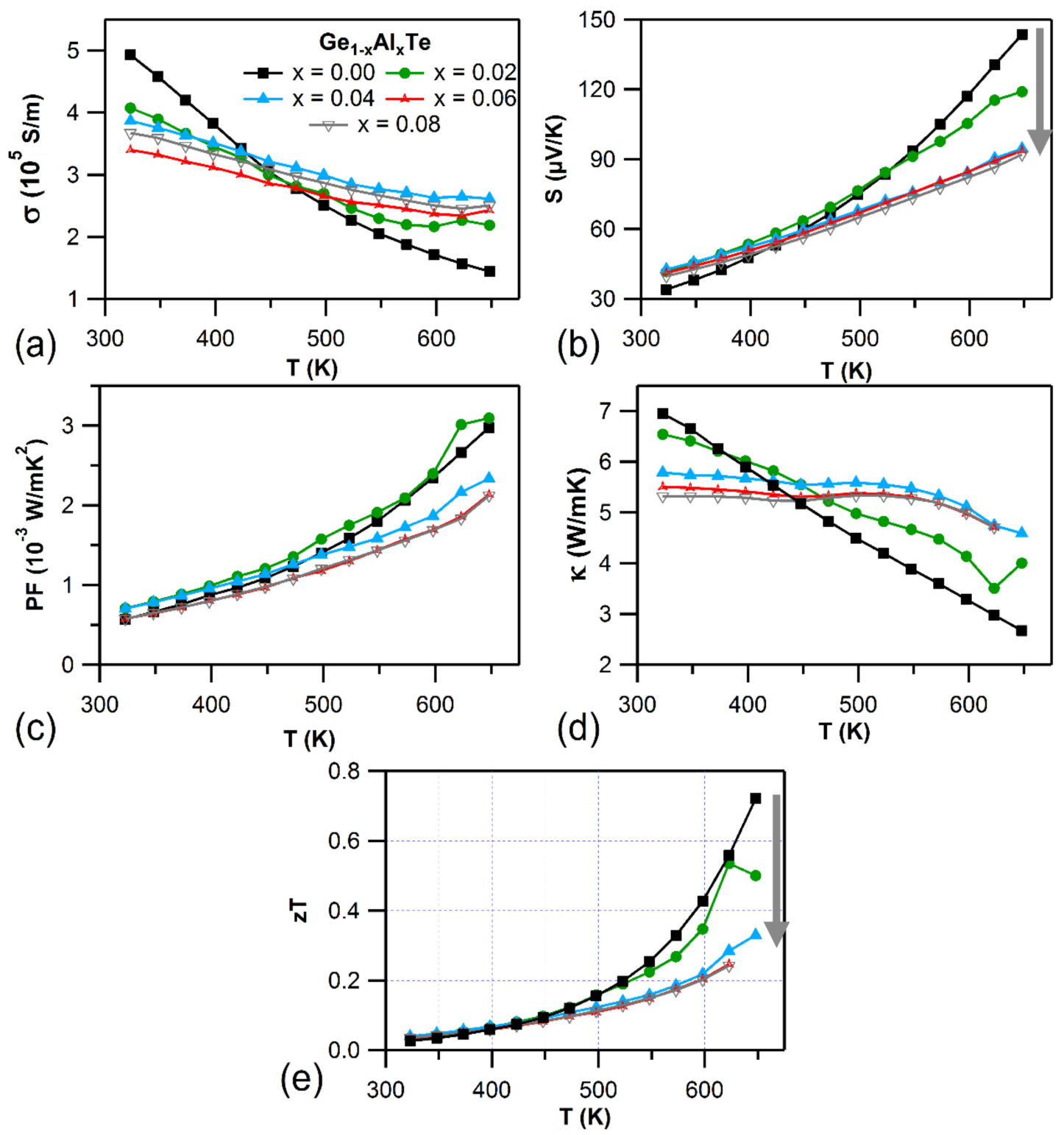

Figure 2. Temperature-dependent (a) electrical conductivity $(\sigma),(\mathbf{b})$ Seebeck coefficient $(S)$, and (c) power factor $\left(\mathrm{PF}=S^{2} \sigma\right),(\mathbf{d})$ total thermal conductivity $(\kappa)$, and (e) figure of merit $(z T)$ for $\mathrm{Ge}_{1-\mathrm{x}} \mathrm{Al}_{\mathrm{x}} \mathrm{Te}$ $(x=0.00-0.08)$ samples.

To have a more cogent understanding on the detrimental effects of these dopants in GeTe, DFT calculations were performed. As we were interested in the high temperature domain for thermoelectric application, these DFT calculations were carried out on $4 \times 4 \times 4$ super-cells derived from the cubic structural arrangement of GeTe. The electronic density of states (DOS) computed for the cubic models of pristine and Al-doped GeTe $\left(\mathrm{Al}_{2} \mathrm{Ge}_{62} \mathrm{Te}_{64} \approx \mathrm{Ge}_{0.97} \mathrm{Al}_{0.03} \mathrm{Te}\right)$ are shown and compared in Figure $4 \mathrm{a}$. The Al-induced resonant states (distinctly indicated by a sharp hump) are present around the Fermi level $\left(E_{\mathrm{F}}\right)$, just like its isoelectronic counterparts In and $\mathrm{Ga}[8,19]$. In such a situation, the Seebeck coefficient is expected to increase, which is not the case with $\mathrm{Al}$ (Figure 2b). 

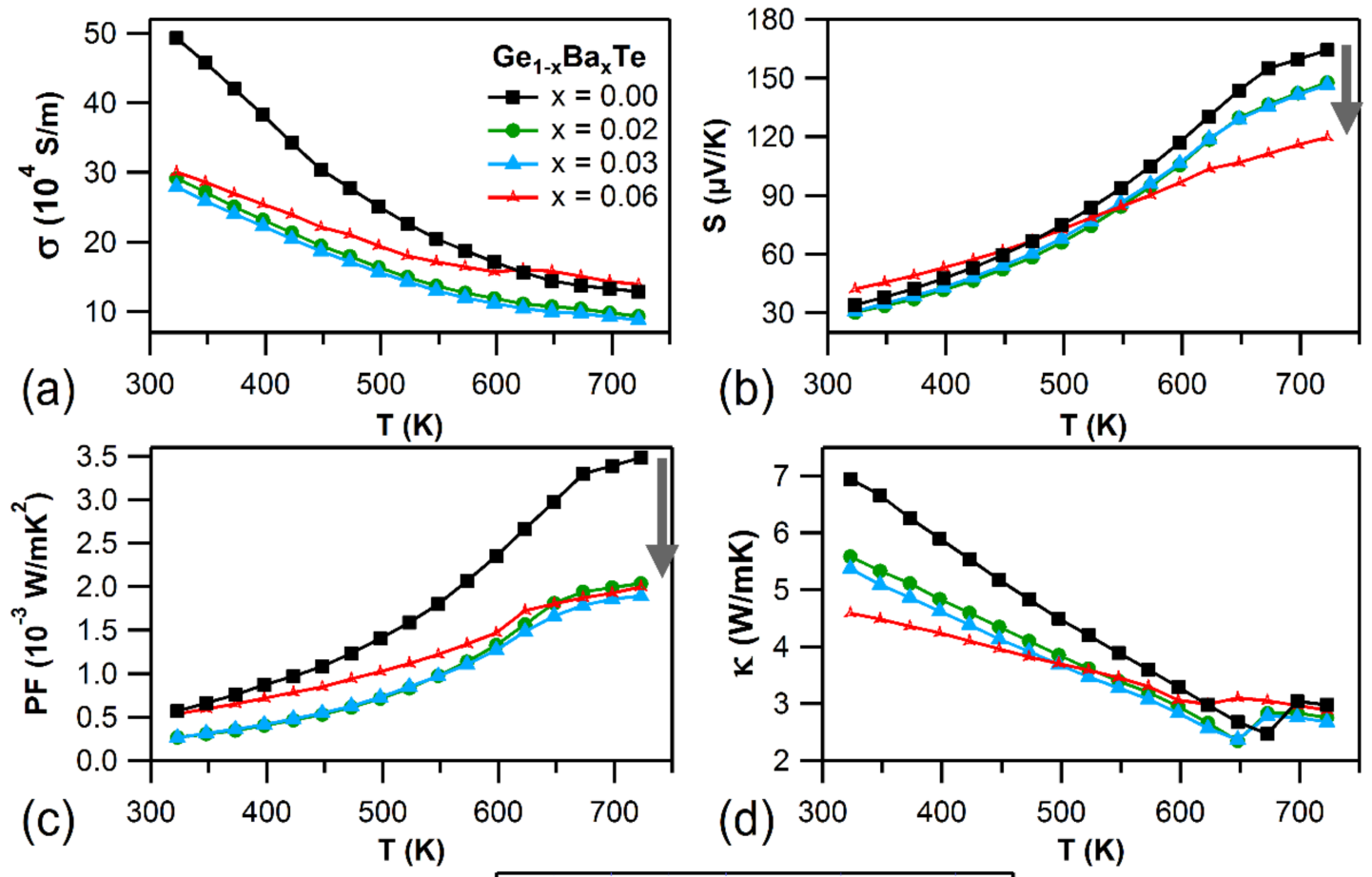

(e)

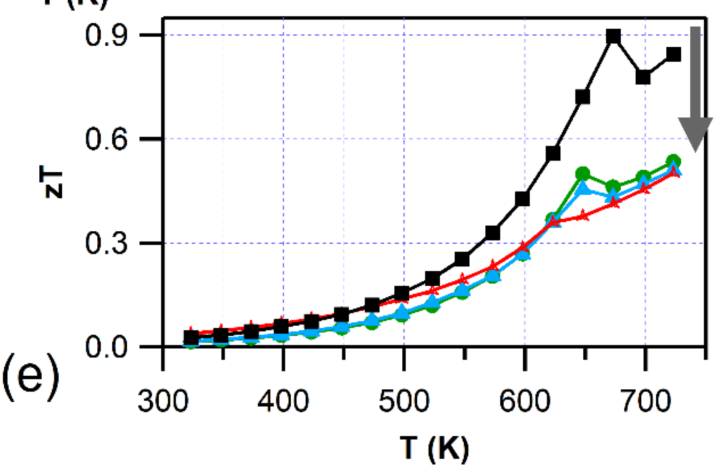

Figure 3. Temperature-dependent (a) electrical conductivity $(\sigma),(\mathbf{b})$ Seebeck coefficient $(S)$, and (c) power factor $\left(\mathrm{PF}=S^{2} \sigma\right)$, (d) total thermal conductivity $(\kappa)$, and (e) figure of merit $(z T)$ for $\mathrm{Ge}_{1-\mathrm{x}} \mathrm{Ba}_{\mathrm{x}} \mathrm{Te}$ $(x=0.00-0.06)$ samples.

Since the DOS calculations yielded inconclusive evidence, electronic band structures were computed to decipher the role of $\mathrm{Al}$ in GeTe. The band structures are plotted in Figure 4 along some high symmetry lines of the cubic Brillouin zone (BZ). The energy difference between light and heavy hole valence bands $\left(\Delta \mathrm{E}_{\mathrm{L} \Sigma}\right)$ for undoped cubic $\mathrm{Ge}_{64} \mathrm{Te}_{64}$ was found to be $64 \mathrm{meV}$, consistent with a recent report [37]. The flat and localized $\mathrm{Al}$ bands are located within the principal band bap (Figure 4d). Al-doping in GeTe increased the energy separation between the light hole and heavy hole valence bands to $179 \mathrm{meV}\left(180 \%\right.$ increment in $\Delta \mathrm{E}_{\mathrm{L} \Sigma}$ when compared to pristine c-GeTe), thus disfavoring the band convergence. According to Mott's relationship, Seebeck coefficient strongly depends on the total DOS effective mass, which in fact is directly proportional to the product of $N_{v}{ }^{2 / 3}$ and the average DOS effective mass for each pocket $\left(N_{v}\right.$ is the number of degenerate carrier pockets) [38]. For GeTe, $N_{v}$ is 4 for the $\mathrm{L}$ band and it increases to 12 for the $\sum$ band [21]. Hence, by increasing the energy separation between $\mathrm{L}$ and $\sum$ bands by doping of $\mathrm{Al}$ to $\mathrm{GeTe}$, the contributions from the additional carriers (from $\sum$ valence band) to electrical transport are lost, thus resulting in a significant reduction in the Seebeck coefficient.

For composition at $x=0.02$, Al-doped GeTe exhibits a thermopower of $\sim 110 \mu \mathrm{V} / \mathrm{K}$ at $623 \mathrm{~K}$. For the same level of doping, the isoelectronic In-doped GeTe is known to exhibit a much higher thermopower of $\sim 200 \mu \mathrm{V} / \mathrm{K}$ at the same temperature [19]. $\Delta \mathrm{E}_{\mathrm{L \Sigma}}$ for the In-doped GeTe (for $\mathrm{InGe}_{63} \mathrm{Te}_{64}$ 
$\approx \mathrm{Ge}_{0.98} \mathrm{ln}_{0.02}$ Te model) is calculated to be $95 \mathrm{meV}$, which is almost two times lower than the $\Delta \mathrm{E}_{\mathrm{L \Sigma}}$ for Al-doped GeTe. It must be noted that, even though the $\Delta \mathrm{E}_{\mathrm{L} \Sigma}$ for In-doped GeTe is marginally higher than that of pristine GeTe, the presence of In-induced resonant states near the $E_{\mathrm{F}}$ has helped it to exhibit a superior thermopower compared to pristine GeTe. However, for the Al-doped GeTe, the beneficial effect of the presence of Al-induced resonant states near the $E_{\mathrm{F}}$ is nullified and severely affected by the extremely large energy separation between the light hole and heavy hole valence bands (179 meV). This explains the juxtaposition of high thermoelectric performance of $\mathrm{Ge}_{0.98} \mathrm{In}_{0.02} \mathrm{Te}$ and low thermoelectric performance of $\mathrm{Ge}_{0.98} \mathrm{Al}_{0.02} \mathrm{Te}$ (isoelectronic) compounds.
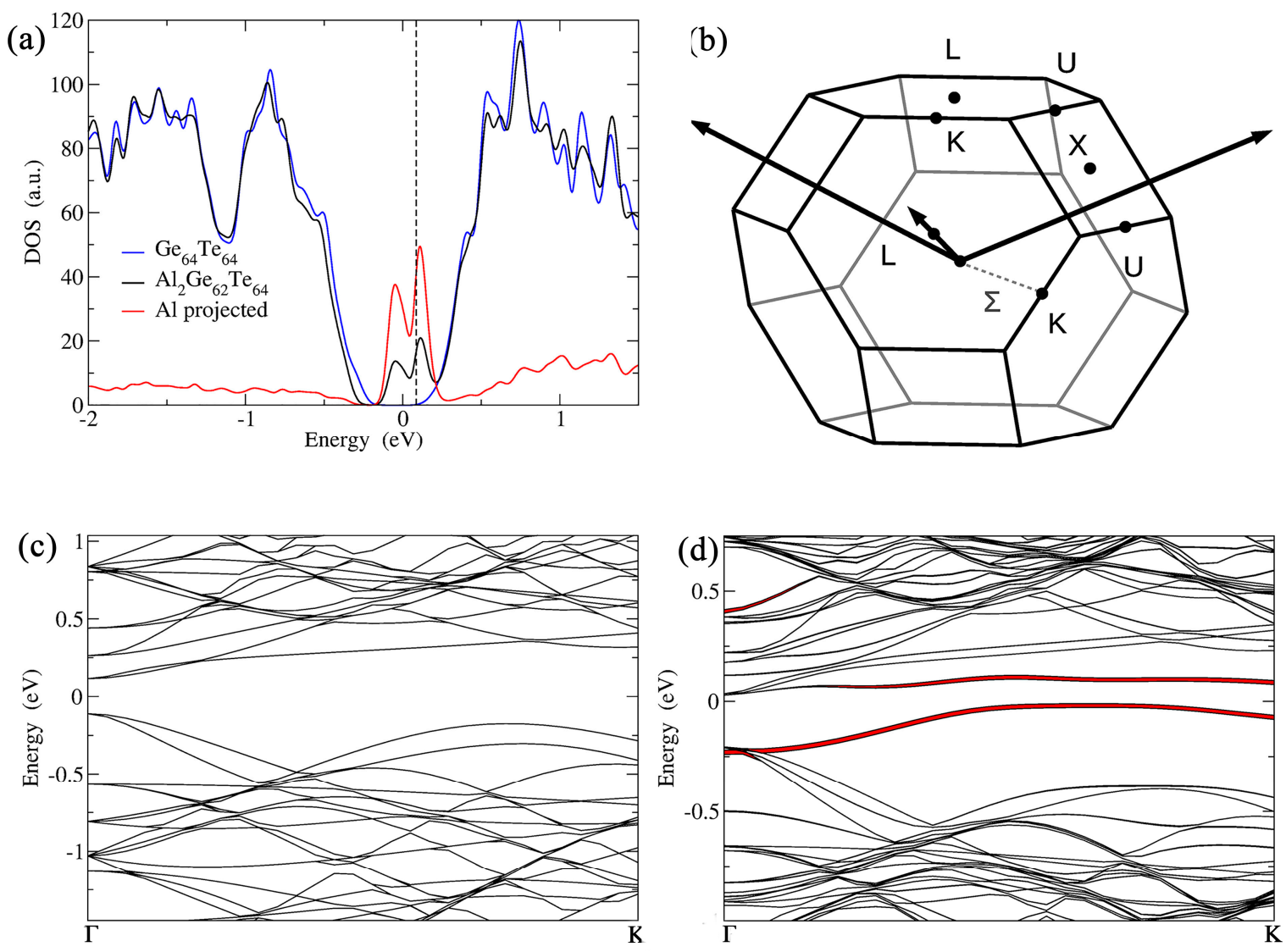

Figure 4. (a) Calculated DOS for $\mathrm{Al}_{2} \mathrm{Ge}_{62} \mathrm{Te}_{64}\left(\mathrm{Ge}_{0.97} \mathrm{Al}_{0.03} \mathrm{Te}\right)$ model, which is compared with that of the pristine cubic phase $\mathrm{Ge}_{64} \mathrm{Te}_{64}(\mathrm{c}-\mathrm{GeTe})$. The Fermi level $\left(E_{\mathrm{F}}\right)$ of pristine c-GeTe is set arbitrarily at $0 \mathrm{eV}$. The dashed line represents the shifted $E_{\mathrm{F}}$ for the doped compositions. Additional Gaussian smearing of $25 \mathrm{meV}$ was applied and the $\mathrm{Al}$ projected DOS is magnified for a better readability of the curves. (b) Brillouin zone of c-GeTe. Band structures for (c) c- $\mathrm{Ge}_{64} \mathrm{Te}_{64}$ using a $4 \times 4 \times 4$ supercell showing band folding in the $\Gamma \rightarrow \mathrm{K}\left(\sum\right)$ direction, and (d) $\mathrm{Al}_{2} \mathrm{Ge}_{62} \mathrm{Te}_{64}\left(\mathrm{Ge}_{0.97} \mathrm{Al}_{0.03} \mathrm{Te}\right)$ highlighting $\mathrm{Al}$ projections. Line thickness is proportional to the projection of the wave function on the $\mathrm{Al}$ (in red) orbitals.

For the case of Ba-doped GeTe, though the DFT results were inconclusive in portraying a clearer picture to explain the reduction in thermopower, it can be attributed to the presence of the secondary phase $\left(\mathrm{Ba}_{2} \mathrm{Ge}_{2} \mathrm{Te}_{5}\right)$. More in-depth studies, like experiments to synthesize this $\mathrm{Ba}_{2} \mathrm{Ge}_{2} \mathrm{Te}_{5}$ phase and measure its transport properties (to estimate the role of contribution of that secondary phase to the overall thermoelectric behavior of the $\mathrm{Ge}_{1-\mathrm{x}} \mathrm{Ba}_{\mathrm{x}} \mathrm{Te}$ compound) are required to understand the causes for Ba-doped GeTe to exhibit lower TE performance. 


\section{Conclusions}

The crystalline ingots of $\mathrm{Ge}_{1-x} \mathrm{Al}_{x} \mathrm{Te}(x=0-0.08)$ and $\mathrm{Ge}_{1-\mathrm{x}} \mathrm{Ba}_{\mathrm{x}} \mathrm{Te}(x=0-0.06)$ were prepared by the vacuum-sealed tube melting route, followed by Spark Plasma Sintering processing. $\mathrm{Al}$ and $\mathrm{Ba}$ are found to not be the best choice of dopants for GeTe, as they subside its thermoelectric performance. Al-doping, unlike other isoelectronic group-13 elements (In and Ga), inflates the hole concentration and drastically increases the energy separation between light and heavy hole bands in GeTe, thus resulting in a reduced thermopower.

Author Contributions: B.S. designed and performed experiments, analyzed the results, and wrote the manuscript. A.G. performed DFT calculations and helped in understanding those results along with J.-F.H., C.B.-P. and B.B. supervised the work. All authors discussed the results and contributed to the final manuscript.

Funding: This research and the article processing charges were funded by European Commission's Horizon 2020 research and innovation program under the Marie Skłodowska-Curie grant (GA. 642557, CoACH-ETN).

Acknowledgments: Prof. Mike Reece is gratefully acknowledged for providing B.S. a secondment opportunity in Queen Mary University of London, where most of the thermoelectric measurements were performed. Régis Gautier and François Cheviré from ISCR Rennes are acknowledged for their constant support.

Conflicts of Interest: The authors declare no conflict of interest.

\section{References}

1. He, J.; Tritt, T.M. Advances in thermoelectric materials research: Looking back and moving forward. Science 2017, 357, eaak9997. [CrossRef] [PubMed]

2. Chen, Z.; Jian, Z.; Li, W.; Chang, Y.; Ge, B.; Hanus, R.; Yang, J.; Chen, Y.; Huang, M.; Snyder, G.J.; et al. Lattice Dislocations Enhancing Thermoelectric PbTe in Addition to Band Convergence. Adv. Mater. 2017, 29, 1606768. [CrossRef] [PubMed]

3. Snyder, G.J.; Toberer, E.S. Complex thermoelectric materials. Nat. Mater. 2008, 7, 105-114. [CrossRef] [PubMed]

4. He, J.; Kanatzidis, M.G.; Dravid, V.P. High performance bulk thermoelectrics via a panoscopic approach. Mater. Today 2013, 16, 166-176. [CrossRef]

5. Zhao, L.-D.; Dravid, V.P.; Kanatzidis, M.G. The panoscopic approach to high performance thermoelectrics. Energy Environ. Sci. 2013, 7, 251-268. [CrossRef]

6. Srinivasan, B.; Gucci, F.; Boussard-Pledel, C.; Cheviré, F.; Reece, M.J.; Tricot, S.; Calvez, L.; Bureau, B. Enhancement in thermoelectric performance of n-type Pb-deficit Pb-Sb-Te alloys. J. Alloys Compd. 2017, 729, 198-202. [CrossRef]

7. Srinivasan, B.; Gautier, R.; Gucci, F.; Fontaine, B.; Halet, J.-F.; Cheviré, F.; Boussard-Pledel, C.; Reece, M.J.; Bureau, B. Impact of Coinage Metal Insertion on the Thermoelectric Properties of GeTe Solid-State Solutions. J. Phys. Chem. C 2018, 122, 227-235. [CrossRef]

8. Srinivasan, B.; Gellé, A.; Gucci, F.; Boussard-Pledel, C.; Fontaine, B.; Gautier, R.; Halet, J.-F.; Reece, M.; Bureau, B. Realizing a Stable High Thermoelectric zT $\sim 2$ over a Broad Temperature Range in $\mathrm{Ge}_{1-x-y} \mathrm{Ga}_{x} \mathrm{Sb}_{y} \mathrm{Te}$ via Band Engineering and Hybrid Flash-SPS Processing. Inorg. Chem. Front. 2018, in press. [CrossRef]

9. Srinivasan, B.; Boussard-Pledel, C.; Bureau, B. Thermoelectric performance of codoped (Bi, In)-GeTe and (Ag, In, Sb)-SnTe materials processed by Spark Plasma Sintering. Mater. Lett. 2018, 230, 191-194. [CrossRef]

10. Perumal, S.; Roychowdhury, S.; Biswas, K. High performance thermoelectric materials and devices based on GeTe. J. Mater. Chem. C 2016, 4, 7520-7536. [CrossRef]

11. Yang, S.H.; Zhu, T.J.; Sun, T.; He, J.; Zhang, S.N.; Zhao, X.B. Nanostructures in high-performance $(\mathrm{GeTe})_{x}\left(\mathrm{AgSbTe}_{2}\right)_{100-x}$ thermoelectric materials. Nanotechnology 2008, 19, 245707. [CrossRef] [PubMed]

12. Schröder, T.; Schwarzmüller, S.; Stiewe, C.; de Boor, J.; Hölzel, M.; Oeckler, O. The Solid Solution Series $(\mathrm{GeTe})_{x}\left(\mathrm{LiSbTe}_{2}\right)_{2}(1 \leq x \leq 11)$ and the Thermoelectric Properties of $(\mathrm{GeTe})_{11}\left(\mathrm{LiSbTe}_{2}\right)_{2}$. Inorg. Chem. 2013, 52, 11288-11294. [CrossRef] [PubMed]

13. Schröder, T.; Rosenthal, T.; Giesbrecht, N.; Maier, S.; Scheidt, E.-W.; Scherer, W.; Snyder, G.J.; Schnick, W.; Oeckler, O. TAGS-related indium compounds and their thermoelectric properties-The solid solution series $(\mathrm{GeTe})_{x} \mathrm{AgIn}_{y} \mathrm{Sb}_{1-y} \mathrm{Te}_{2}(x=1-12 ; y=0.5$ and 1). J. Mater. Chem. A 2014, 2, 6384-6395. [CrossRef] 
14. Samanta, M.; Roychowdhury, S.; Ghatak, J.; Perumal, S.; Biswas, K. Ultrahigh Average Thermoelectric Figure of Merit, Low Lattice Thermal Conductivity and Enhanced Microhardness in Nanostructured $(\mathrm{GeTe})_{x}\left(\mathrm{AgSbSe}_{2}\right)_{100-x}$. Chem. Eur. J. 2017, 23, 7438-7443. [CrossRef] [PubMed]

15. Fahrnbauer, F.; Souchay, D.; Wagner, G.; Oeckler, O. High Thermoelectric Figure of Merit Values of Germanium Antimony Tellurides with Kinetically Stable Cobalt Germanide Precipitates. J. Am. Chem. Soc. 2015, 137, 12633-12638. [CrossRef] [PubMed]

16. Gelbstein, Y.; Davidow, J. Highly efficient functional $\mathrm{Ge}_{x} \mathrm{~Pb}_{1-x} \mathrm{Te}$ based thermoelectric alloys. Phys. Chem. Chem. Phys. 2014, 16, 20120-20126. [CrossRef] [PubMed]

17. Perumal, S.; Roychowdhury, S.; Biswas, K. Reduction of thermal conductivity through nanostructuring enhances the thermoelectric figure of merit in $\mathrm{Ge}_{1-x} \mathrm{Bi}_{x} \mathrm{Te}$. Inorg. Chem. Front. 2016, 3, 125-132. [CrossRef]

18. Wu, D.; Zhao, L.-D.; Hao, S.; Jiang, Q.; Zheng, F.; Doak, J.W.; Wu, H.; Chi, H.; Gelbstein, Y.; Uher, C.; et al. Origin of the High Performance in GeTe-Based Thermoelectric Materials upon $\mathrm{Bi}_{2} \mathrm{Te}_{3}$ Doping. J. Am. Chem. Soc. 2014, 136, 11412-11419. [CrossRef] [PubMed]

19. Wu, L.; Li, X.; Wang, S.; Zhang, T.; Yang, J.; Zhang, W.; Chen, L.; Yang, J. Resonant level-induced high thermoelectric response in indium-doped GeTe. NPG Asia Mater. 2017, 9, e343. [CrossRef]

20. Yang, L.; Li, J.Q.; Chen, R.; Li, Y.; Liu, F.S.; Ao, W.Q. Influence of Se Substitution in GeTe on Phase and Thermoelectric Properties. J. Electron. Mater. 2016, 45, 5533-5539. [CrossRef]

21. Perumal, S.; Roychowdhury, S.; Negi, D.S.; Datta, R.; Biswas, K. High Thermoelectric Performance and Enhanced Mechanical Stability of p-type $\mathrm{Ge}_{1-x} \mathrm{Sb}_{x} \mathrm{Te}$. Chem. Mater. 2015, 27, 7171-7178. [CrossRef]

22. Lee, J.K.; Oh, M.W.; Kim, B.S.; Min, B.K.; Lee, H.W.; Park, S.D. Influence of Mn on crystal structure and thermoelectric properties of GeTe compounds. Electron. Mater. Lett. 2014, 10, 813-817. [CrossRef]

23. Rosenberg, Y.; Gelbstein, Y.; Dariel, M.P. Phase separation and thermoelectric properties of the $\mathrm{Pb}_{0.25} \mathrm{Sn}_{0.25} \mathrm{Ge}_{0.5} \mathrm{Te}$ compound. J. Alloys Compd. 2012, 526, 31-38. [CrossRef]

24. Li, J.; Zhang, X.; Lin, S.; Chen, Z.; Pei, Y. Realizing the High Thermoelectric Performance of GeTe by Sb-Doping and Se-Alloying. Chem. Mater. 2017, 29, 605-611. [CrossRef]

25. Samanta, M.; Biswas, K. Low Thermal Conductivity and High Thermoelectric Performance in $(\mathrm{GeTe})_{1-2 x}(\mathrm{GeSe})_{x}(\mathrm{GeS})_{x}$ : Competition between Solid Solution and Phase Separation. J. Am. Chem. Soc. 2017, 139, 9382-9391. [CrossRef] [PubMed]

26. Perumal, S.; Bellare, P.; Shenoy, U.S.; Waghmare, U.V.; Biswas, K. Low Thermal Conductivity and High Thermoelectric Performance in Sb and Bi Codoped GeTe: Complementary Effect of Band Convergence and Nanostructuring. Chem. Mater. 2017, 29, 10426-10435. [CrossRef]

27. Li, J.; Zhang, X.; Chen, Z.; Lin, S.; Li, W.; Shen, J.; Witting, I.T.; Faghaninia, A.; Chen, Y.; Jain, A.; et al. Low-Symmetry Rhombohedral GeTe Thermoelectrics. Joule 2018, 2, 976-987. [CrossRef]

28. Srinivasan, B.; Boussard-Pledel, C.; Dorcet, V.; Samanta, M.; Biswas, K.; Lefèvre, R.; Gascoin, F.; Cheviré, F.; Tricot, S.; Reece, M.; et al. Thermoelectric Properties of Highly-Crystallized Ge-Te-Se Glasses Doped with $\mathrm{Cu} /$ Bi. Materials 2017, 10, 328. [CrossRef] [PubMed]

29. Srinivasan, B.; Fontaine, B.; Gucci, F.; Dorcet, V.; Saunders, T.G.; Yu, M.; Cheviré, F.; Boussard-Pledel, C.; Halet, J.-F.; Gautier, R.; et al. Effect of the Processing Route on the Thermoelectric Performance of Nanostructured $\mathrm{CuPb}_{18} \mathrm{SbTe}_{20}$. Inorg. Chem. 2018, 57, 12976-12986. [CrossRef] [PubMed]

30. Srinivasan, B.; Cui, S.; Prestipino, C.; Gellé, A.; Boussard-Pledel, C.; Ababou-Girard, S.; Trapananti, A.; Bureau, B.; Di Matteo, S. Possible Mechanism for Hole Conductivity in Cu-As-Te Thermoelectric Glasses: A XANES and EXAFS Study. J. Phys. Chem. C 2017, 121, 14045-14050. [CrossRef]

31. Kresse, G.; Joubert, D. From ultrasoft pseudopotentials to the projector augmented-wave method. Phys. Rev. B 1999, 59, 1758-1775. [CrossRef]

32. Kresse, G.; Furthmüller, J. Efficient iterative schemes for ab initio total-energy calculations using a plane-wave basis set. Phys. Rev. B 1996, 54, 11169-11186. [CrossRef]

33. Perdew, J.P.; Burke, K.; Ernzerhof, M. Generalized Gradient Approximation Made Simple. Phys. Rev. Lett. 1996, 77, 3865-3868. [CrossRef] [PubMed]

34. Wang, H.; LaLonde, A.D.; Pei, Y.; Snyder, G.J. The Criteria for Beneficial Disorder in Thermoelectric Solid Solutions. Adv. Funct. Mater. 2013, 23, 1586-1596. [CrossRef]

35. Roychowdhury, S.; Shenoy, U.S.; Waghmare, U.V.; Biswas, K. Tailoring of Electronic Structure and Thermoelectric Properties of a Topological Crystalline Insulator by Chemical Doping. Angew. Chem. Int. Ed. 2015, 54, 15241-15245. [CrossRef] [PubMed] 
36. Zhang, L.J.; Qin, P.; Han, C.; Wang, J.L.; Ge, Z.H.; Sun, Q.; Cheng, Z.X.; Li, Z.; Dou, S.X. Enhanced thermoelectric performance through synergy of resonance levels and valence band convergence via $Q / I n(Q$ = Mg, Ag, Bi) co-doping. J. Mater. Chem. A 2018, 6, 2507-2516. [CrossRef]

37. Hong, M.; Chen, Z.-G.; Yang, L.; Zou, Y.-C.; Dargusch, M.S.; Wang, H.; Zou, J. Realizing zT of 2.3 in $\mathrm{Ge}_{1-x-y} \mathrm{Sb}_{x} \mathrm{In}_{y} \mathrm{Te}$ via Reducing the Phase-Transition Temperature and Introducing Resonant Energy Doping. Adv. Mater. 2018, 30, 1705942. [CrossRef] [PubMed]

38. Pei, Y.; Shi, X.; LaLonde, A.; Wang, H.; Chen, L.; Snyder, G.J. Convergence of electronic bands for high performance bulk thermoelectrics. Nature 2011, 473, 66-69. [CrossRef] [PubMed]

(C) 2018 by the authors. Licensee MDPI, Basel, Switzerland. This article is an open access article distributed under the terms and conditions of the Creative Commons Attribution (CC BY) license (http:/ / creativecommons.org/licenses/by/4.0/). 